\title{
Mathability of EMC Emission Testing for Mission Crucial Devices in GTEM Waveguide
}

\author{
Zoltán Kvasznicza $^{1}$, István Gyurcsek ${ }^{1}$, György Elmer ${ }^{1}$, \\ Viktor Bagdán ${ }^{2}$, Ildikó Horváth ${ }^{3}$
}

${ }^{1}$ Department of Electrical Networks, ${ }^{2}$ Department of Automation, Faculty of Engineering and Information Technology, University of Pécs

Boszorkány út 2, H-7624 Pécs, Hungary;

${ }^{3}$ VR-Learing Research Lab, Apáczai Faculty, Széchenyi István University Egyetem tér 1, H-9022 Győr, Hungary

kvasznicza@mik.pte.hu,gyurcsek.istvan@mik.pte.hu, elmer@mik.pte.hu, bagdan.viktor@mik.pte.hu, horvath.ildiko@ga.sze.hu

Abstract: In connection with investigations related to mathability and to applications of computer-assisted methods for studying a validation of Electromagnetic Compatibility $(E M C)$ tests is presented. This paper presents a validation of Electromagnetic Compatibility (EMC) tests performed in Gigahertz Transverse Electromagnetic (GTEM) cells as an alternative method to tests performed at Open Area Test Sites (OATS) or expensive anechoic chambers. The equipment selected for the inspection is widely used in electronic devices of crucial reliability expectations like medical measurements or electronic components for transport and industrial process control. This special engineering topic gives a good example of the wide applicability of mathability.

Keywords: Cognitive Infocommunication; mathability; EMC

\section{Introduction}

Mathability refers to a branch of Cognitive Infocommunications [1, 2] that investigates any combination of artificial and natural cognitive capabilities relevant to mathematics, including a wide spectrum of areas ranging from lowlevel arithmetic operations to high-level symbolic reasoning Mathability: Emulating and Enhancing Human Mathematical Capabilities. The concept was introduced in the paper [3] related to the $4^{\text {th }}$ IEEE International Conference on Cognitive Infocommunications (CogInfoCom) [1, 2] in 2013. Some of its further general properties were presented in the papers [4, 5] and in the book [1]. Its educational aspects were investigated, besides the Virtual Reality (VR) education [6-14], and [15-20]. In this paper, we would like to contribute to 
mathability and to computer-based methods for investigations of mathematical problems investigations. Our aim is to present a computer-assisted method for validation of Electromagnetic Compatibility (EMC) tests performed in Gigahertz Transverse Electromagnetic (GTEM) cells as an alternative method to tests performed at Open Area Test Sites (OATS) or expensive anechoic chambers.

\section{Professional Background}

The rapid development of the technology and implementation of electrical and electronic parts in devices used on a daily basic lead to the evolution of numerous standards and legislations with the aim to protect users and devices themselves from electromagnetic radiation. Market demands urge companies to create devices with wireless communication and charging which can result in interferences. High-speed digital and analogue circuits create direct radiation from their printed circuit boards (PCBs) becoming a major concern for electromagnetic compatibility engineers. Electronic systems of the future require higher bandwidth with lower power consumption to handle the massive amount of data, especially for large memory systems, high-definition displays, and high-performance microprocessors. A detailed review of the EMC analysis of PCBs is given in [21] by Er-Ping Li et al.

Electromagnetic Compatibility (EMC) is a concept of ensuring the proper operation of different electric and electronic devices without mutual interference. EMC standards refer in many times to tests performed at OATS and in anechoic chambers. However, using a standard anechoic chamber for EMC tests can burden the manufacturer of the EUT with high costs and if a GTEM cell is available then it could offer an alternative method for these tests. Because they are less expensive, GTEM cells are convenient alternatives. GTEM cells are as accurate as anechoic chambers and can be used if the EUT is small enough to fit into the cell.

The work presented in this paper has been done on the basis of the relevant standard IEC 61000-4-20 issued by the International Electrotechnical Commission in 2010 [22].

This paper is organized as follows: After summarizing the related and most relevant work the applied method for measurement and obtained test results, achieved in GTEM cell, are described. Finally, future works planned and conclusions of the paper are listed. 


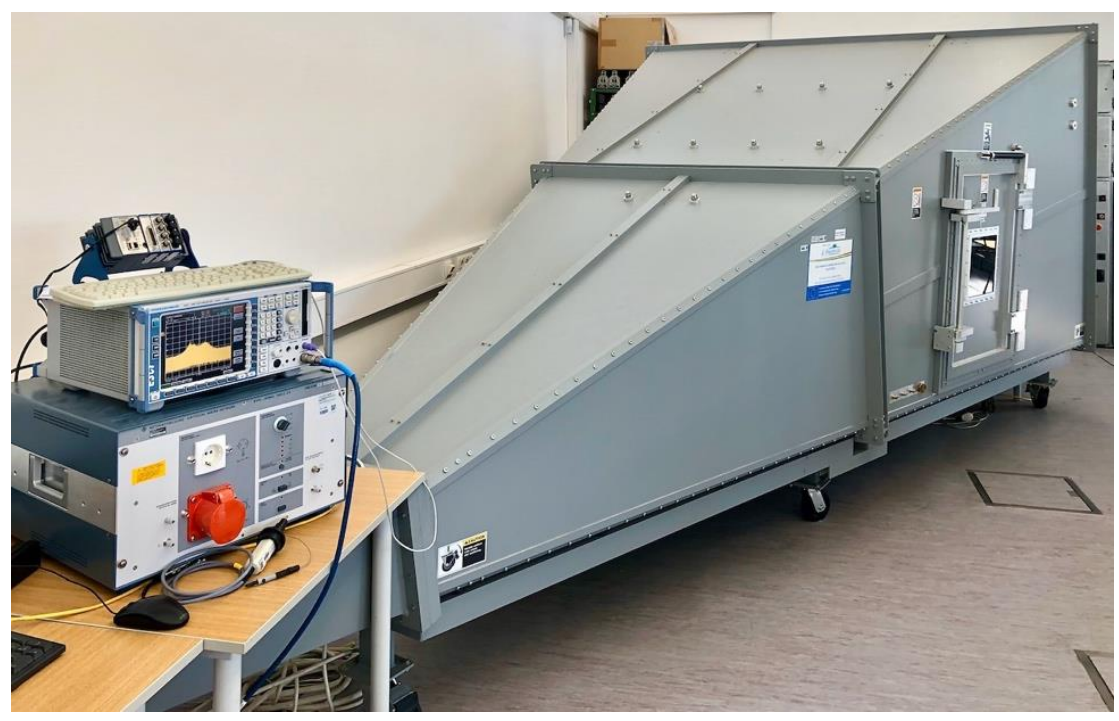

Figure 1

The GTEM cell used with a spectrum analyzer connected

\section{Related Work}

In the field of EMC numerous papers are presented, papers most relative to our work are shortly described in this section in [23]. In [24] authors test RFID tag using GTEM cell and an anechoic chamber and compose a result analysis which shows a correlation between the results but future works have to be done for the use of GTEM cells with standardized EMC test equipment. A probe calibration of a GTEM cell is done in [25]. Different types of probes were tested in a frequency range of 1 to $6 \mathrm{GHz}$. Because of the distribution of the electric field in a GTEM cell, the nom-uniform calibration results have to be compared with the results of a reference method achieved in an anechoic chamber. The GTEM cell is tested as ab alternative method for a radiated immunity test in [26]. Work in [27] proposes an error compensation method for improving the accuracy of the GTEM cell applied for radiated EMI measurements.

Although most of the work in the field of EMC using GTEM cells report on testing and improving GTEM cell accuracy, some studies like [28] propose a method for how to develop, simulate and construct cost-effective GTEM cells. 


\section{GTEM Cell Measurement}

\subsection{The GTEM Cell}

A GTEM cell is a quadratic conical waveguide with the angle of $20^{\circ}$ in a vertical direction and an angle of $30^{\circ}$ in horizontal direction. The wave impedance of this line is $50 \Omega$. Because of its construction, there is no reflection inside, additionally ensured by the absorbing wall opposite to the peak of the cell. The conducting part of the waveguide is called a septum with a resistance network at its end. The septum is a conductive metal plate, the width of which is 0.636 times of the width of the outer conductor. One end of the septum is a standard coaxial connector and its other end is connected to the back wall of the cell through a resistance network. Thanks to its quadratic conical construction only planar electromagnetic waves can be considered in its inside with a good approximation. Applying a GTEM cell both the electromagnetic emission and electromagnetic immunity (or susceptibility) can be tested but in case of immunity tests external generators are necessary to provide radio frequency interference (RFI) signals as disturbances. Scope of this paper is to give validation of EMC emission tests performed in a GTEM cell as an alternative method to tests performed at OATS or anechoic chambers.

The schematic structure of the GTEM cell is shown in Fig. 2 with the allowed location area -for the Equipment Under Test (EUT), signed. Supposing planar waves with intensity $\mathrm{E}$ of a homogeneous electric field and characteristic impedance ZC of the TEM waveguide the power $\mathrm{P}$ at the height of hEUT in the cell is given in (1).

$P=\frac{\left(E \cdot h_{E U T}\right)^{2}}{Z_{C}}$

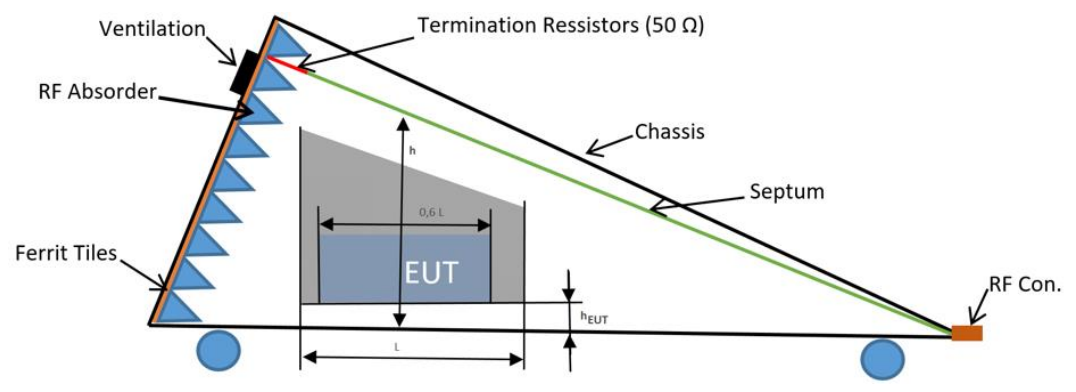

Figure 2

Structure of a GTEM cell 
For achieving results appropriate to be compared with those obtained with the OATS method a test in a GTEM cell includes three tests performed with three different positions of the EUT as shown in Fig. 3.

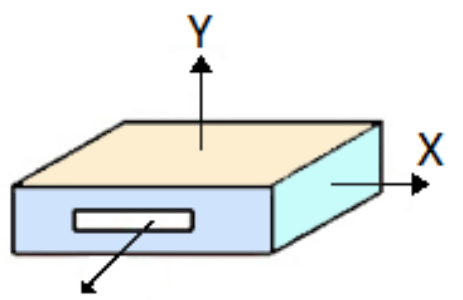

Z 1 .

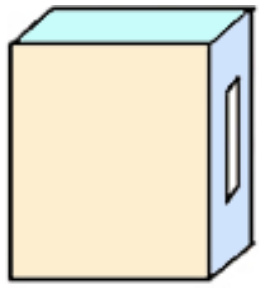

2.

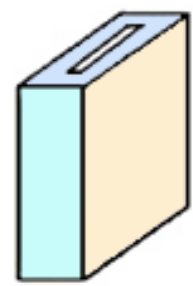

3.

Figure 3

Applied EUT positions $\mathrm{x}, \mathrm{y}, \mathrm{z}$ of tested EUT

The referred standard distinguishes between so-called 'Small EUTs' (the largest dimension of the EUT is shorter than the shortest wavelength of the measurement signal) and 'Large EUTs' (the largest dimension of the EUT is longer than the shortest wavelength of the measurement signal OR the EUT has external wireconnection).

In the case of emission tests, the power emitted by the EUT is calculated from the test results obtained with three EUT positions as given in (2) [29].

$P=\frac{\eta_{0}}{3 \pi} \cdot \frac{k_{0}^{2}}{e^{2} Z_{c}} \cdot S^{2}$

where

$S=\sqrt{V_{X}^{2}+V_{Y}^{2}+V_{Z}^{2}}$

$k_{0}=\frac{2 \pi}{\lambda}$

$\eta_{0}=\sqrt{\frac{\mu}{\varepsilon}}=120 \pi \cong 377 \Omega$

and $\mathrm{V}_{\mathrm{X}}, \mathrm{V}_{\mathrm{Y}}, \mathrm{V}_{\mathrm{Z}}$ are voltages measured in three EUT positions, $\mathrm{S}$ is the root-sumsquare of these voltages, $\mathrm{k}_{0}$ is the wavenumber, $\eta_{0}$ is the free open space impedance and $\mathrm{e}$ is the TEM mode field factor of the cell used in test and determined by the geometry of the cell. 
To find the correlation with the OATS test results the EUT emissions over a ground plane can be simulated by assuming that the total radiated power, as estimated by the TEM waveguide tests, is the same as that emitted by a dipole replacing the EUT. Maximum field strength $\mathrm{E}_{\max }$ on an OATS is given in (6).

$E_{\max }=g_{\max } \cdot \frac{\eta_{0} \cdot k_{0}}{2 \cdot \pi \cdot e} \cdot \frac{S}{\sqrt{Z_{C}}}$

where $g_{\max }$ is the geometry factor of the receiving antenna in the GTEM cell.

\subsection{The Standard IEC 61000-4-20}

The standard IEC 61000-4-20 is an international standard defining emission and immunity test methods for electrical and electronic equipment with the help of various types of transverse electromagnetic (TEM) waveguides [9]. These types include open structures (for example striplines and electromagnetic pulse simulators) and closed structures (for example TEM cells). These structures can be further classified as one, two, or multi-port TEM waveguides. The frequency range depends on the specific test requirements and the specific TEM waveguide type.

The objective of this standard is to describe

- $\quad$ TEM waveguide characteristics including typical frequency ranges and EUT-size limitations;

- $\quad$ EM waveguide validation methods for EMC tests;

- $\quad$ the definition of EUT;

- $\quad$ test set-ups, procedures, and requirements for radiated emission testing in TEM waveguides and

- $\quad$ test set-ups, procedures, and requirements for radiated immunity testing in TEM waveguides.

\subsection{The Equipment under Test}

Thanks to our industrial contributor for testing purposes we are provided with a couple of 'Equipment Under Test' (EUT) devices of crucial EMC requirements in practical applications. The tested EUT is a TPS54560 step-down converter applied widely for supplying power in electronic devices. It is designed to provide up to 5 A output current from an input voltage source. Input voltage can be in the range from $4.5 \mathrm{~V}$ up to $60 \mathrm{~V}$. Detailed information about EUT is given in datasheet [10]. In Fig. 4 the photo of this EUT is shown. 
EMC tests of these DC-DC converters have high importance in several fields of electronic devices with the need of mission-crucial applications like medical measurements, automotive industry, etc., hence they are widely used for example in mobile medical test equipment, onboard ambulance cars, ... for supplying the electronic and control units at different voltage levels. According to the standard described above EMC tests for these elements are necessary.

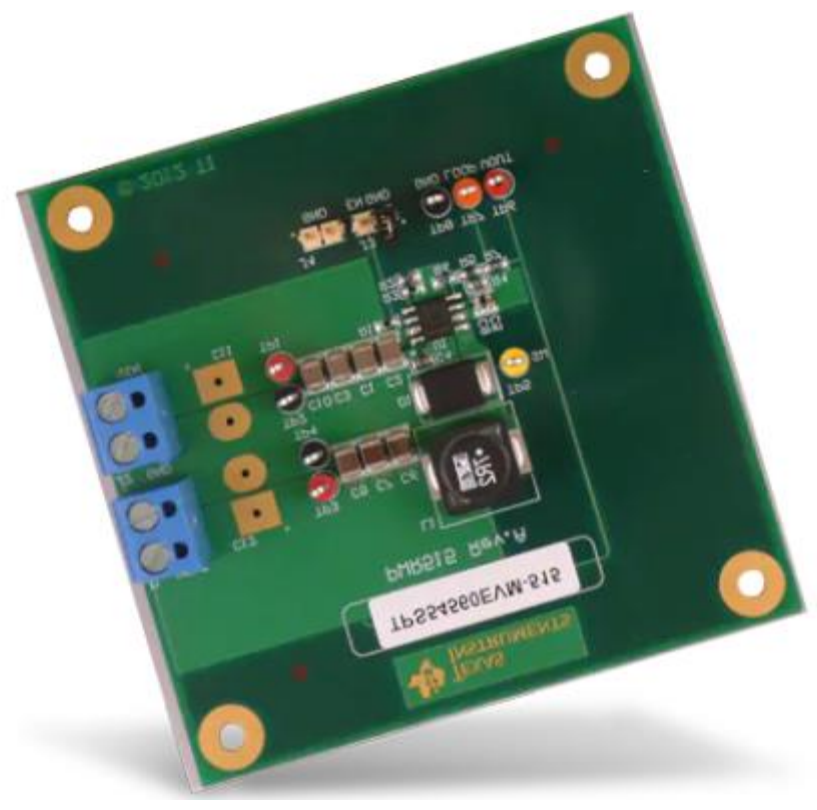

Figure 4

EUT (TPS54560EVM-515 Board)

\subsection{Test Results}

Tests have been performed at the Faculty of Technology and Informatics of the University of Pécs in the laboratory of the Department of Electrical Networks taking into account every step listed in the standard IEC 61000-4-20.

The applied test receiver was a Rohde \& Schwarz ESCI EMI spectrum analyzer and for fetching, displaying, and analyzing the obtained data the software EMC32 has been used.

The R\&S ${ }^{2}$ EMC32 Measurement Software runs on 32-bit and 64-bit operating systems from Microsoft and offers a common user interface for electromagnetic interference (EMI) and electromagnetic susceptibility (EMS) measurements. 
Key features:

- measurement of disturbance voltage, disturbance power, and disturbance field strength;

- use inproduct certification and precompliance testing during development;

- inline with commercial, automotive, and military standards;

- flexible adaptation to requirements of various EMC applications;

- libraries of limit lines for various international product standards and correction factors (antenna transducers, probes, LISNs, etc.);

- integrated calibration concept, flexible report generator (HTML, RTF, PDF);

- $\quad$ software operates as a virtual instrument.

These tests have been performed in the frequency band of $30 \mathrm{MHz}-1 \mathrm{GHz}$ with a resolution of $120 \mathrm{kHz}$. The measuring time for each point was $0.1 \mathrm{~ms}$. Complete test results for a EUT are given in the following.

The spectrums of measured voltages in $\mathrm{X}, \mathrm{Y}$, and $\mathrm{Z}$ directions are given in Fig. 5, Fig. 6, and Fig. 7. The calculated root sum square voltage spectrum of measured voltages is shown in Fig. 8.

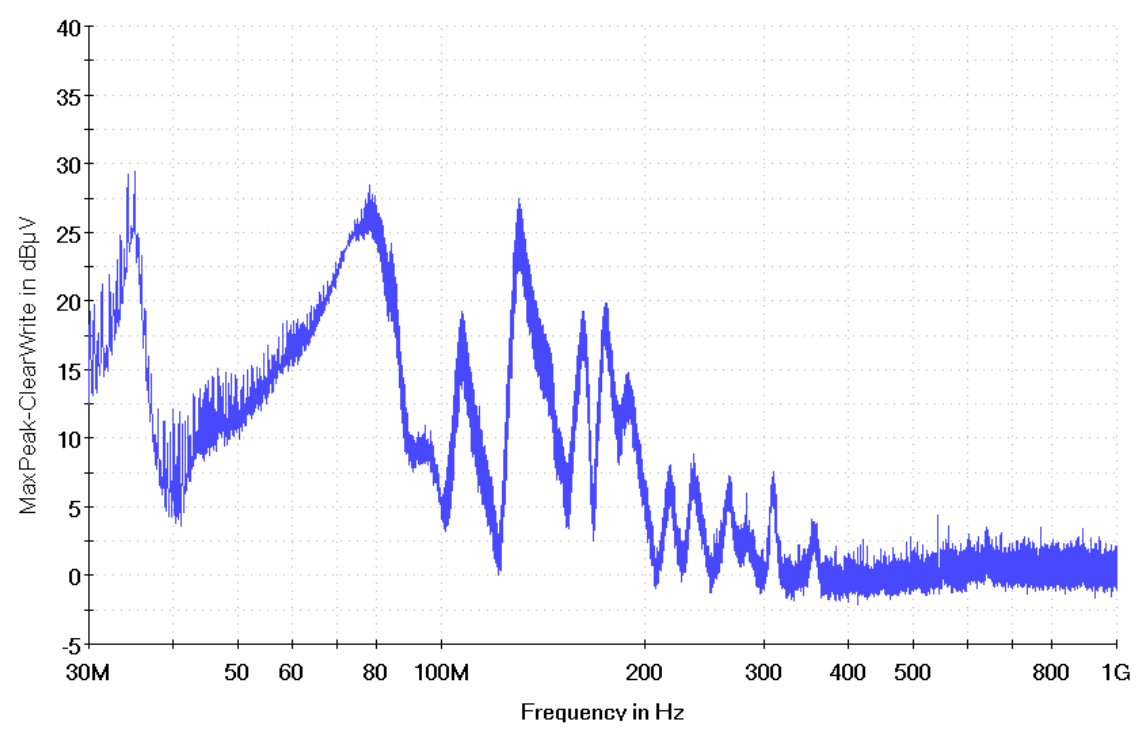

Figure 5

Measured spectrum for the direction X 


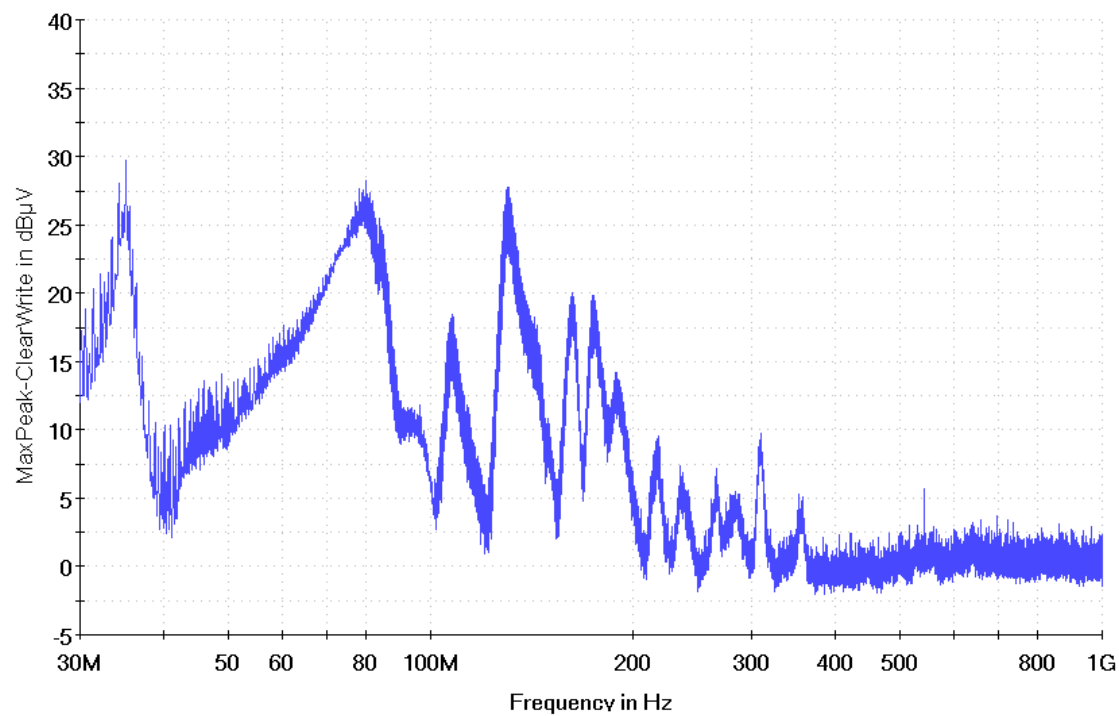

Figure 6

Measured spectrum for the direction $\mathrm{Y}$

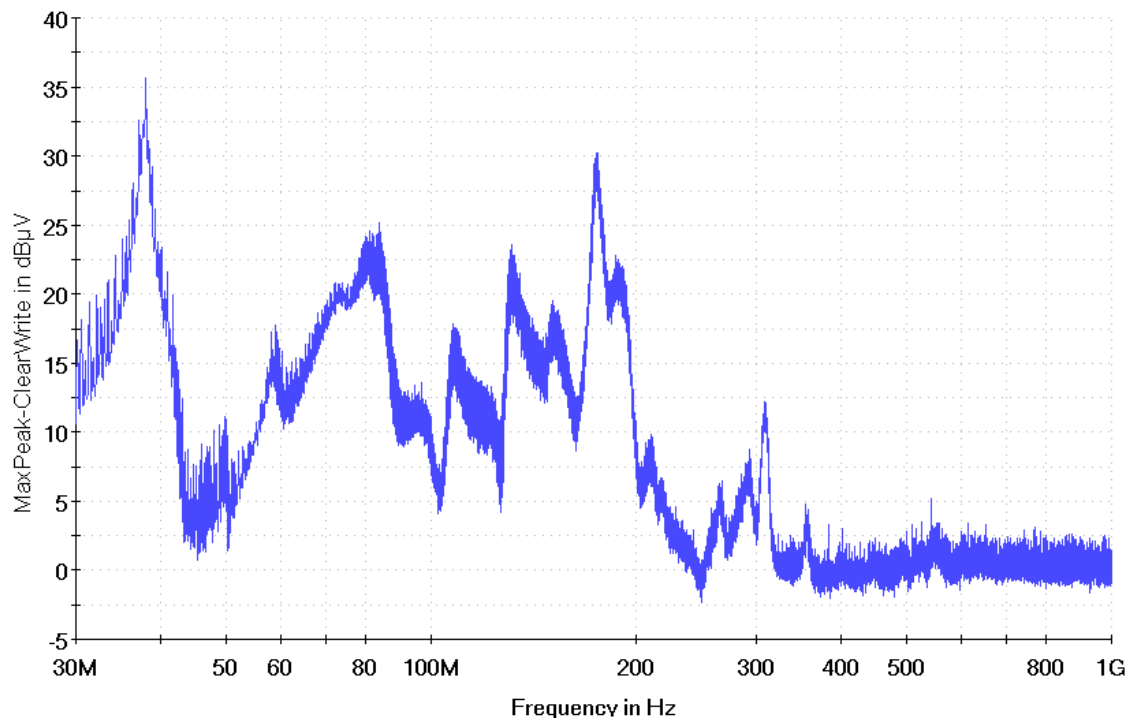

Figure 7

Measured spectrum for the direction $\mathrm{Z}$ 


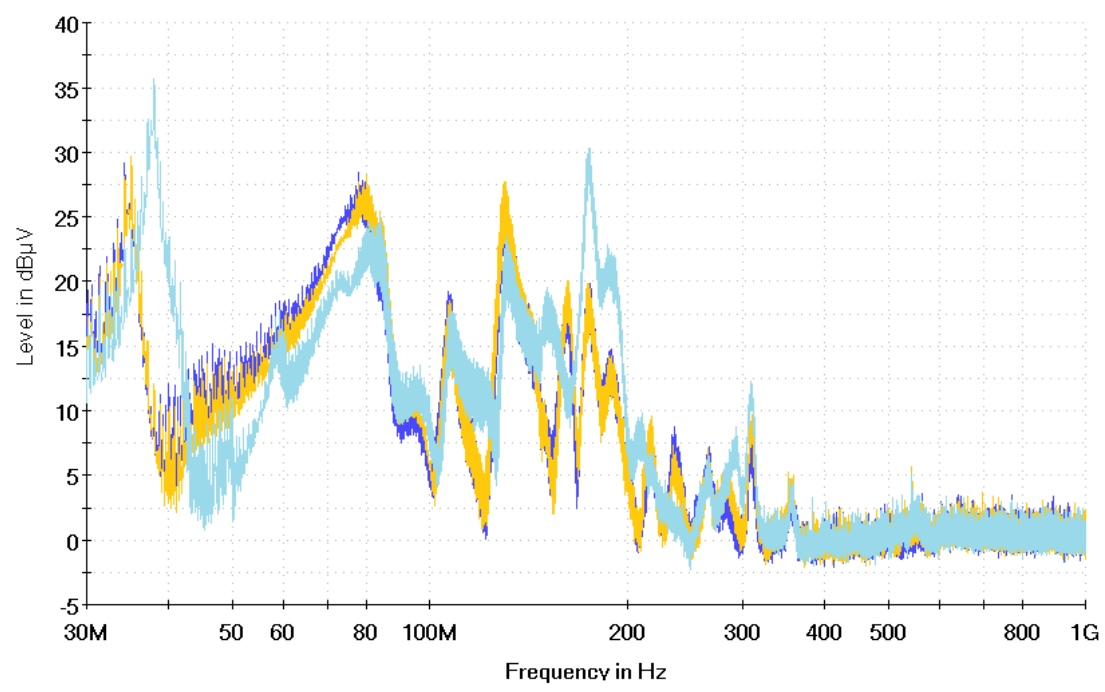

Figure 8

The calculated root sum square result of test

The electric field intensity, based on the OATS voltage spectrum, calculated in correlation procedure, is given in Fig. 9.

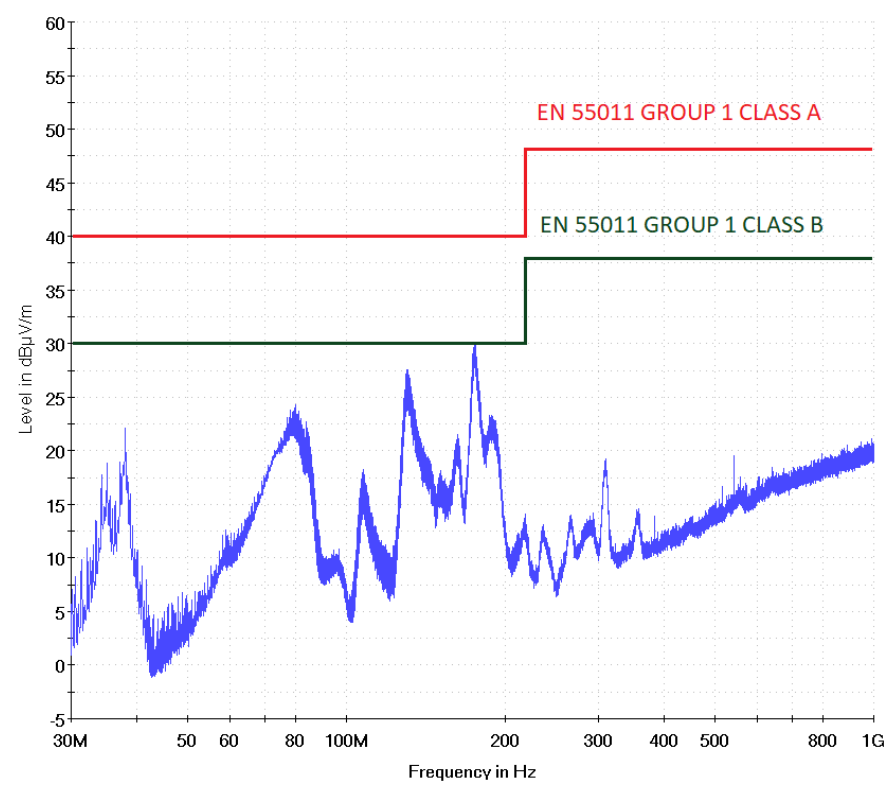

Figure 9

The correlated OATS (10m) electric field intensity spectrum with the limits required in EN55011 standard 
The main reason for the electromagnetic emission of the observed EUT is its switching mode of operation. The responsible waveforms, measured on a fourchannel-oscilloscope (LeCroy WaveRunner 6030), are illustrated in Fig. 10. The brown-colored signal is the input voltage (CH1), the red one is the output voltage $(\mathrm{CH} 2)$, the blue signal is the switching pulse $(\mathrm{CH} 3)$ and the green is the internal feedback (CH4). The reasonable harmonic components, existing on each measured component, are well noticed causing the harmful electromagnetic noise emission. The higher load of the EUT the higher EMC emission is detected.

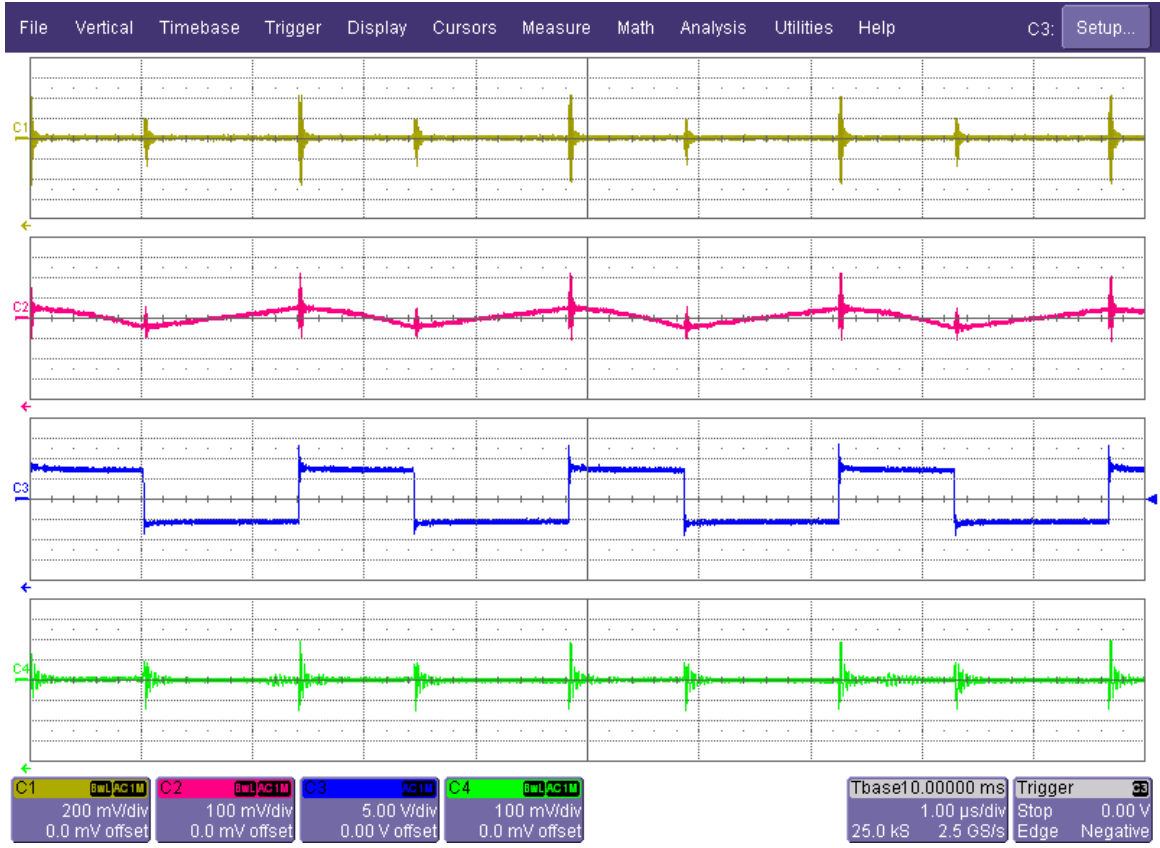

Figure 10

Internal waveforms of the EUT shown on oscilloscope

Decreasing the load will decrease the emission but it can also be controlled by the sophisticated construction of the step-down converter. EMC test-based fine-tuning of the switching period or filtering the input and output voltage could also have beneficial effects on the level of the electromagnetic emission.

It is important to emphasize the EUT is tested according to the EN55011) standard, referred to medical devices and for IT applications, for example. The intensity of the electric field is below the limit along the full frequency range in this case. If the measured noise spectrum of the observed EUT was analyzed against EN55012 standard [12] that is applied for the automotive industry (for example), the result would be different. 


\section{Conclusions}

During the last decade, EMC testing with GTEM cells became more applicable due to its lower cost and accuracy improvements. This paper gives an overview of the GTEM cell, the test methods and the relevant standard with test results achieved with EUTs, chosen by their crucial practical applications. Test results show a correlation between a test with a GTEM cell and those with OATS.

The voltage tests performed in GTEM waveguide is a cost-effective alternative test method in EMC emission tests for crucial electronic elements with the help of mathematical big data processing, visualization, animation, and virtualization.

The OATS and SAC related E-field data are converted form the GTEM based voltage data applying the correlation procedure.

The converted E-field data of tested EUTs are to be compared to limit requirements described in appropriate standards.

In future work, the E-field data resulted in this work will be validated by reference data obtained in OATS tests applied in most cases in the fields of related industry.

Based on the validation of the work enhanced GTEM waveguide test and correlation method is to be developed for accuracy improvement.

\section{Acknowledgement}

The research project is conducted at the University of Pécs, Hungary, within the framework of the Biomedical Engineering Project of the Thematic Excellence Programme 2019 (TUDFO/51757-1/2019-ITM).

\section{References}

[1] Baranyi P. and Csapo A. and Sallai G.: Cognitive Infocommunications (CogInfoCom), Springer International Publishing Switzerland, 2015, p. 191, (978-3-319-19607-7, http://www.springer.com/us/book/ 9783319196077\#aboutBook

[2] Baranyi $\mathrm{P}$ and Csapo A., Definition and Synergies of Cognitive Infocommunication, Acta Polytechnica Hungarica, 2012, Vol. 9, No. 1, pp. 67-83 (ISSN 1785-8860)

[3] P. Baranyi and A. Gilányi: Mathability: emulating and enhancing humanmathematicalcapabilities, in $4^{\text {th }}$ IEEEInternationalConference on Cognitive Infocommunications (CogInfoCom) IEEE, 2013, pp. 555-558

[4] P. Baranyi, A. Csapo, and P. Varlaki: An overview of research trends in coginfocom in $18^{\text {th }}$ International Conference on Intelligent Engineering Systems (INES) IEEE, 2014, pp. 181-186

[5] M. Török, M. J. Tóth, and A. Szőllösi: Foundations and perspectives of mathability in relation to the coginfocom domain, in $4^{\text {th }}$ IEEE International 
Conference on Cognitive Infocommunications (CogInfoCom) IEEE, 2013, pp. $869-872$

[6] I. Horváth, A. Sudár: Factors Contributing to the Enhanced Performance of the MaxWhere 3D VR Platform in the Distribution of Digital Information, Acta Polytechnica Hungarica, 2018, Vol. 15, No. 3, pp. 149-173

[7] B. Lampert, A. Pongrácz, J. Sipos, A. Vehrer, I. Horvath: MaxWhere VRlearning improves effectiveness over clasiccal tools of e-learning, Acta Polytechnica Hungarica, 2018, Vol. 15, No. 3, pp. 125-147

[8] I. Horváth: The educoaching method in the service of efficient teaching of disruptive technologie, chapter in book Cognitive Infocommunications Theory and Applications, Springer e-book 2018, Vol. 13, pp. 349-365, ISSN 2193-942X, ISBN 978-3-319-95996-2

[9] A. Csapo, I. Horváth, P. Galambos and P. Baranyi: VR as a Medium of Communication: from Memory Palaces to Comprehensive Memory Management In Cognitive Infocommunications (CogInfoCom), Budapest, $2018,9^{\text {th }}$ IEEE International Conference on Cognitive Infocommunications (CogInfoCom)

[10] Kvasznicza, Z.: Teaching electrical machines in a 3D virtual space. In Cognitive Infocommunications (CogInfoCom), $20178^{\text {th }}$ IEEE International Conference on Cognitive Infocommunications (CogInfoCom) pp. 000385000388

[11] I. Horváth: Innovative engineering education in the cooperative VR environment, In: Proceedings of $7^{\text {th }}$ IEEE Conference on Cognitive Infocommunications. Wrocław, Poland, 2016, 16-18.10.2016. Budapest: IEEE Hungary Section, pp. 359-364 (ISBN 978-1-5090-2644-9; 978150902645-6)

[12] Borbála Berki: Desktop VR as a Virtual Workspace: a Cognitive Aspect, Acta Polytechnica Hungarica, 2019, Vol. 16, No. 2, pp. 219-231

[13] J. Baranyiné Kóczy, L. I. Komlósi: Revisiting literacy. Changing learning paradigms in digital culture Argumentum, Debreceni Egyetemi Kiadó, 2019, Vol. 15, pp. 117-132

[14] A. Kövári, J. Katona, I. Heldal, C. Helgesen: Examination of Gaze Fixations Recorded during the Trail Making Test, $10^{\text {th }}$ IEEE Conference on Cognitive Infocommunications (CogInfoCom), Naples, Italy, 2019

[15] G. Gy. Borus and A. Gilányi: On a computer program for solving systems of functional equations. In $4^{\text {th }}$ IEEE International Conference on Cognitive Infocommunications (CogInfoCom), Budapest, 2013, Vol. 2, p. 939

[15] G. Gy. Borus, A. Gilányi: Solving systems of linear functional equations with computer. In $4^{\text {th }}$ IEEE International Conference on Cognitive Infocommunications (CogInfoCom), Budapest, 2013, Vol. 2, pp. 559-562 
[16] G. Gy. Borus, A. Gilányi: Computer assisted solution of systems of two variable linear functional equations. Aequationes Math., to appear, 2020

[17] K. Chmielewska, A. Gilányi: Educational context of mathability. Acta Polytechnica Hungarica, 2018, Vol. 15, No. 5, pp. 223-237

[18] K. Chmielewska, A. Gilányi: Computer assisted activating methods in education. In $10^{\text {th }}$ IEEE International Conference on Cognitive Infocommunications (CogInfoCom), Naples, Italy, 2019, pp. 241-246

[19] K. Chmielewska, A. Gilányi, A. Lukasiewicz: Mathability and mathematical cognition. In $7^{\text {th }}$ IEEE Conference on Cognitive Infocommunications (CogInfoCom), Wroclaw, Poland, 2016, pp. 245-250

[20] A. Gilányi, N. Merentes, R. Quintero: Mathability and an animation related to a convex-like property. In $7^{\text {th }}$ IEEE Conference on Cognitive Infocommunications (CogInfoCom), Wroclaw, Poland, 2016, pp. 227-232

[21] Er-Ping Li et al: Progress Review of Electromagnetic Compatibility Analysis Technologies for Packages, Printed Circuit Boards, and Novel Interconnects, IEEE Transactions on Electromagnetic Compatibility, 2010, Vol. 52, No. 2, pp. 248-265

[22] "International Electrotechnical Commission" [Online] Available: www.iec.ch [Accessed: 25-Sep-2018]

[23] M. Ramdani et al: The Electromagnetic Compatibility of Integrated Circuits-Past, Present, and Future, IEEE Transactions on Electromagnetic Compatibility, 2009, Vol. 51, No. 1, pp. 78-100

[24] A. Luz and F. Costalonga: RFID tag tests: Comparison between GTEM cell and anechoic chamber results, in 2014 IEEE Brasil RFID, Sao Paulo, Brazil, 2014, pp. 50-53

[25] I. Wu, S. Ishigami, K. Gotoh, and Y. Matsumoto: Probe calibration by using a different type of probe as a reference in GTEM cell above $1 \mathrm{GHz}$, IEICE Electronics Express, 2010, Vol. 7, No. 6, pp. 460-466

[26] M. A. Salhi, S. Cakir, M. Cinar, B. Tektas, and M. Cetintas: GTEM cell as an alternative method for radiated immunity tests: A comparison with an anechoic chamber, in International Symposium on Electromagnetic Compatibility - EMC EUROPE, Wroclaw, Poland, 2016, pp. 251-256

[27] B. Zhao, M. Zhao, and D. Chen: Using voltage-driven model to correlate GTEM cell and anechoic chamber measurement, in IEEE International Instrumentation and Measurement Technology Conference Proceedings, Graz, Austria, 2012, pp. 2165-2168

[28] T. Stander and S. Sinha: Development, simulation and construction of costeffective GTEM cells, in $23^{\text {rd }}$ International Conference Radioelektronika (RADIOELEKTRONIKA), Pardubice, 2013, pp. 39-44 
[29] "IEC61000-4-20." Testing and measurement techniques - Emission and immunity testing in transverse electromagnetic (TEM) waveguides, May 2010

[30] "Evaluation Module for the TPS54560 Step-Down Converter," 2013, p. 22

[31] EN 55011:2009 Industrial, scientific and medical equipment- Radiofrequency disturbance characteristics Limits and methods of measurement

[32] EN 55012:2007+A1 Vehicles, boats, and internal combustion engines Radio disturbance characteristics — Limits and methods of measurement for the protection of off-board receivers

[33] Timothy Hegarty: An overview of radiated EMI specifications for power supplies, Texas Instruments, Phoenix, AZ, 2018 